\title{
Study on Masonry Blocks Fabricated from Waste Paper and Industrial Waste Spent Catalyst
}

\author{
Talal Mohammed Sultan Al Shibani, Sanjay Govind Patil*, and Adnan M Nidal Shms Eddin
}

\begin{abstract}
Disposal of industrial waste is a major concern all over the world due to stringent laws enforced by government agencies. This has motivated many researchers to recycle these wastes into an innovative construction material. Presently, these wastes are recycled to some extent, however the majority of them disposed to landfill. Thus, leading to environmental issues. Similarly, industrial waste, such as spent catalyst and waste papers are hardly recycled in Oman. The present paper discusses the study carried out on Masonry Blocks (MB) fabricated using spent catalyst, lime and waste paper sludge. MB-1 block consists of lime and waste paper sludge as filler material, whereas spent catalyst and waste paper sludge is used in the MB-2 block. For both masonry bocks ordinary Portland cement is used as binder. Laboratory investigation carried out in the material testing laboratory at Caledonian College of Engineering in terms of compressive strength, creep, alternate wetting and drying and thermal conductivity test, revealed that blocks fabricated with spent catalyst showed better performance compared to blocks fabricated with lime.
\end{abstract}

Keywords-Spent Catalyst, Paper Sludge, Compressive Strength, Creep, Thermal Conductivity

\section{Introduction}

The building industry is one of the largest industries in Oman and there is a growing demand for building materials in the last two decades, such as cement, sand, natural stones, bricks, steel, glass, wood, etc. The demand for the construction material is going to increase in coming years as the total value of projects planned in Oman is around $\$ 163.5 \mathrm{bn}$ which includes a range of sectors like energy, manufacturing, transportation and utilities and is equivalent to twice the Oman's annual GDP [1]. This expected overall growth is seen as a clear indication of a booming market for construction materials. To meet this demand, building material suppliers have exploited natural resources. This has led government agencies to enforce stringent laws in maintaining natural resources for a sustainable future. Further, this has motivated many researchers to adopt a concept of recycling waste materials into an innovative building material to meet the large demand of construction materials.

Mr Talal Mohammed Sultan Al Shibani

Caledonian College of Engineering

Sultanate of Oman

Dr Sanjay Govind Patil* (corresponding author),

Caledonian College of Engineering

Sultanate of Oman

Mr Adnan M Nidal Shms Eddin

Caledonian College of Engineering

Sultanate of Oman
Many researchers [2-11] have worked on recycling waste paper, waste paper sludge, ash granulated blast furnace slag, straw bale, fly ash, Styrofoam, recycled aggregates, plastic cans, agriculture waste to develop low density masonry bricks. Others [12- 15] carried out studies on mechanical, structural behavior of the composite wall system and physical parameters. For completion of this subject a review paper by Naganathan [16] on "Development of Bricks from Waste Material: A review Paper" could be referred. According to Mohammed [9] around $45 \%$ of waste papers are recycled annually and around $55 \%$ of waste paper is thrown away or goes into the landfill and Oman is no exception. Similarly, the disposal of spent catalyst which is generated by oil refineries in Oman as a result of the cracking process of petroleum oil is a major concern [17]. Presently, spent catalyst is stacked in barren land, causing environmental problems. The authors felt that, not using these resources and simply dumping it in barren land is a national loss, therefore, there is a need to recycle this waste into a usable construction material. The present paper, discusses the possible usage of spent catalyst and waste paper to fabricate masonry blocks as construction material.

\section{Experimental Investigation}

This section discusses the materials used and their properties. Further, it discusses the experimental programme carried out in developing masonry blocks from waste papers, spent catalyst and lime.

\section{A. Materials Used}

Cement: In the present investigation Ordinary Portland Cement (OPC) of 43 grades conforming to BS 12 was used.

Spent Catalyst: Spent catalyst (SC) used in the present study is considered as a waste product generated from locally available oil refineries in Oman as a result of the cracking process of petroleum oil consisting primarily of silicates, aluminates and other secondary elements. Specific gravity of SC is noted as 2.49. Heavy elements such as arsenic (As), cadmium (Cd), chromium $(\mathrm{Cr})$, lead $(\mathrm{Pb})$, copper $(\mathrm{Cu})$, Nickel $(\mathrm{Ni})$, and Zinc (Zn) were noted, however, they are within the limits specified by the Environmental Protection Agency (EPA) - US and could be used as ingredient in developing masonry blocks. The $\mathrm{pH}$ and electrical conductivity of spent catalyst were noted as 4.06 and $751 \mu \mathrm{s} / \mathrm{cm}$ respectively. This indicates that they are not alkaline and less corrosive in nature.

Waste papers and sludge: Locally available newspapers, magazines, and office waste papers were collected from different sources. These papers were shredded in a shredding machine and soaked in water for 24 hours and then stirred mechanically to obtain a paper pulp (Figure 1). The $\mathrm{pH}$ and electrical conductivity of paper pulp 
were 9.01 and $372 \mu \mathrm{s} / \mathrm{cm}$ respectively, which indicates that they are not alkaline.

Lime: locally available white lime powder was used in the present investigation consisting primarily of calcium oxides and tricalcium silicates.

Water: Potable water meeting the BS standards was used in the present investigation. Required amount of water was added to have a workable papercrete.

\section{B. Experimental Programme}

\section{Mix proportions}

In the present research work, masonry blocks were developed from waste paper pulp, SC, lime and OPC. Two mixes were prepared as shown in Table I. MB-1 block consists four parts of paper sludge and half part of lime by weight, whereas MB-2 block consists four parts of paper sludge and half part of spent catalyst. For both masonry

TABLE I: MIX PROPORTIONS OF MASONRY BLOCK

\begin{tabular}{|c|c|c|c|c|}
\hline \multirow{2}{*}{ Mix } & \multicolumn{4}{|c|}{ Ratio's in Weight } \\
\cline { 2 - 5 } & $\begin{array}{c}\text { Portland } \\
\text { Cement }\end{array}$ & $\begin{array}{c}\text { Paper } \\
\text { Sludge }\end{array}$ & $\begin{array}{c}\text { Spent } \\
\text { Catalyst }\end{array}$ & Lime \\
\hline MB-1 & 1 & 4 & - & 0.5 \\
\hline MB-2 & 1 & 4 & 0.5 & - \\
\hline
\end{tabular}

blocks, one part OPC by weight was used as a binder. For both mixes water was added to have enough moisture and workability to cast the blocks. Figure 1 shows the sludge preparation from waste paper.

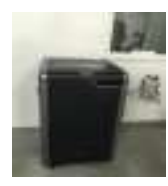

Shredder Machine

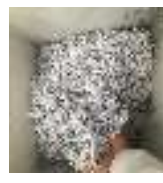

Shredded paper

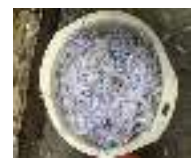

Shredded paper soaked in
water for 24 hrs

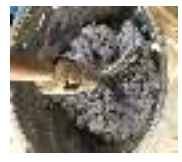

Sludge preparation
Figure 1. Sludge preparation from waste papers

\section{Casting of masonry blocks}

Figure 2 shows the steel moulds fabricated locally. In the present work two moulds of size $40 \times 20 \times 20 \mathrm{~cm}$ and $40 \times$ $20 \times 10 \mathrm{~cm}$ is used. These are the standard sizes of masonry blocks used in Oman. A special arrangement to this mold is done to press the cast block once the mould is completely filled. Care has been taken, that no water is drained out from the mould. The quantities required for each mix are calculated by weight as per the proportions shown in Table 1. Mixing was carried out in a mixer as shown in Figure 2. Water was added to the mix so that the entire mix is moist enough to fill the mould.

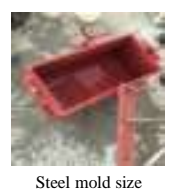

Steel mold size
$40 \times 20 \times 20 \mathrm{~mm}$

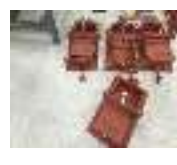

Steel mold size $40 \times 20 \times 10 \mathrm{~mm}$

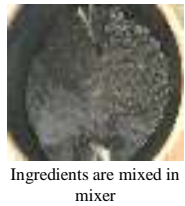

mixer

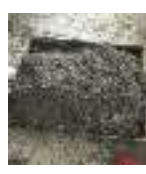

Mix ready to cast masonry blocks
Figure 2. Mixing of ingredients under progress
Mould was filled with three layers and compacted using the tamping rod. Figure 3 shows the filling of mix into the mould. After two hours, the moulds were dismantled and the blocks kept for air drying.
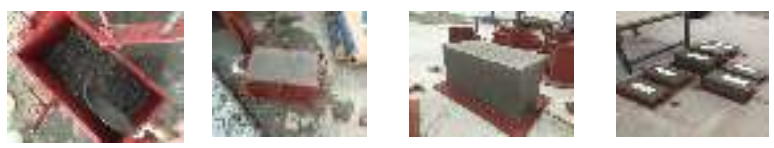

Casting of masonry block under process

Air Drying of blocks

Figure 3. Casting and air drying of masonry blocks

\section{Compressive strength test}

The compressive strength test was carried out on both blocks (MB-1 and MB-2) to check higher stiffness and lower deformation. Compressive strength for both the blocks were tested after 14 days from date of casting, Universal testing machine (UTM) of 100 ton capacity was used to test the compressive strength of the masonry blocks as shown in Figure 4.
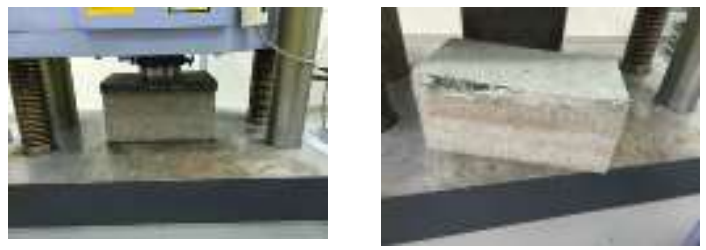

Figure 4. Compressive strength test and failure of masonry block

\section{Creep test}

This test is used to see how the material behaves when it is subjected to a constant compressive load for a longer period of time. A block size of $40 \times 20 \times 10 \mathrm{~cm}$ was chosen for creep test for MB-1 and MB-2 mixes. Creep apparatus was fabricated locally. It was designed in such a way that it allows us to measure vertical creep. Through cantilever steel rod, a load of $150 \mathrm{Kg}$ was suspended and transmitted to the masonry block through steel plate as shown in Figure 5. Gauge was attached to the steel plate to measure the deformation. The deformation was measured with a sensitivity of $0.01 \mathrm{~mm}$. Each masonry block was subjected to a constant load of $150 \mathrm{Kg}$ for a longer period, approximately three to four weeks until the increment of deformation from one day with respect to another was almost zero.

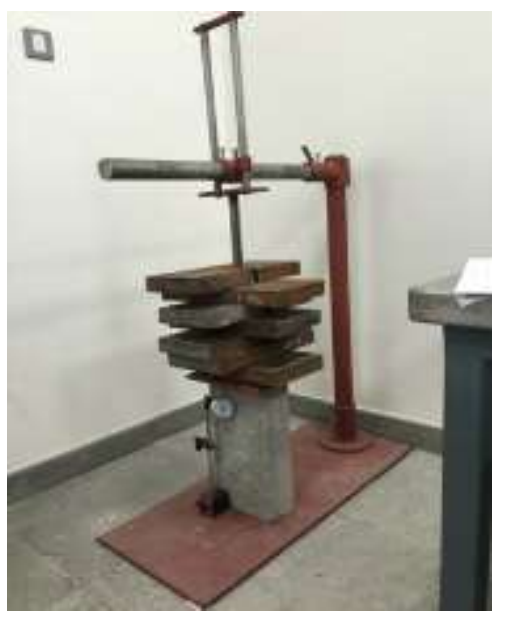

Figure 5. Experimental set up for creep test 


\section{Alternate wetting and drying test}

This test is carried out to study the durability aspects, such as changes in shape, deterioration and compressive strength after a fixed number of alternate wetting and drying cycle. In the present investigation, MB-1 and MB-2 blocks were tested for alternate wetting and drying. The blocks were immersed in clean water at $20 \pm 2{ }^{\circ} \mathrm{C}$ for complete 24 hours duration. The blocks, were removed from the water and placed on a wire mesh to drain for a minute. The blocks were then dried out with a cloth to clear surface water and then immediately weighed. After weighing the wet block, it was dried in a ventilated oven to approximately $105 \pm 5^{\circ} \mathrm{C}$ for 24 hours. This completes the one cycle of alternate wetting and drying. This test was repeated for around 8 cycles. Figure 6 shows the test on alternate wetting and drying.
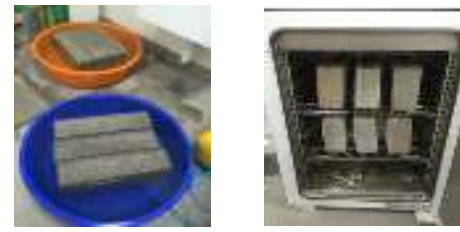

Figure 6. Alternate wetting and drying experimental set up

\section{Thermal conductivity test}

This test was carried out to test the ability of MB-1 and MB-2 block to conduct heat. The instrument (KD2 Pro.) was used to measure the thermal conductivity. The experimental setup is shown in Figure 7. In the present research work TR-1 sensor was used. The sensor needle is $10 \mathrm{~cm}$ long and $2.4 \mathrm{~mm}$ in diameter. The needle was properly inserted into the block and then the KD2 pro instrument was turned on. The instrument takes around five minutes to measure the thermal conductivity. This test was carried out on three different samples with a gap of around 15-20 minutes. An average of three readings was taken as the thermal conductivity of the block.

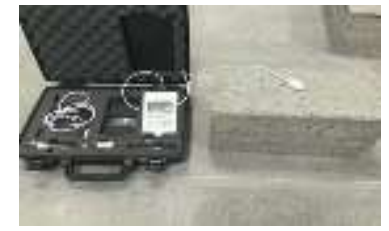

Figure 7. Experimental set up for thermal conductivity test

\section{Results and Discussion}

\section{A. Compressive strength of masonry blocks}

The compressive strength results of MB-1 and MB-2 blocks after 14 days of air drying from the date of casting are shown in Table II and Figure 8. The compressive strength test was carried out for MB-1 and MB-2 block for $40 \times 20 \times 20 \mathrm{~mm}$ and $40 \times 20 \times 10 \mathrm{~mm}$ size. It is observed that the compressive strength test is seen higher in smaller size blocks $(10 \mathrm{~mm})$ in both the mixes compared to bigger size blocks $(20 \mathrm{~mm})$. This may be due to linear elastic fracture mechanics (LEFM) size effect. Blocks fabricated using lime and paper sludge has shown low compressive strength compared to the blocks fabricated with spent catalyst and paper sludge. It is also observed that the masonry blocks squeeze like rubber under compressive load.

\section{TABLE II: COMPRESSIVE STRENGTH OF MASONRY BLOCKS}

\begin{tabular}{|c|c|c|}
\hline Mix & Size (mm) & $\begin{array}{l}\text { Average compressive strength after } \\
14 \text { days of air drying }\left(\mathrm{N} / \mathrm{mm}^{2}\right)\end{array}$ \\
\hline \multirow{2}{*}{ MB-1 } & $40 \times 20 \times 20$ & 0.78 \\
\hline & $40 \times 20 \times 10$ & 1.28 \\
\hline \multirow{2}{*}{ MB-2 } & $40 \times 20 \times 20$ & 4.92 \\
\hline & $40 \times 20 \times 10$ & 5.09 \\
\hline
\end{tabular}

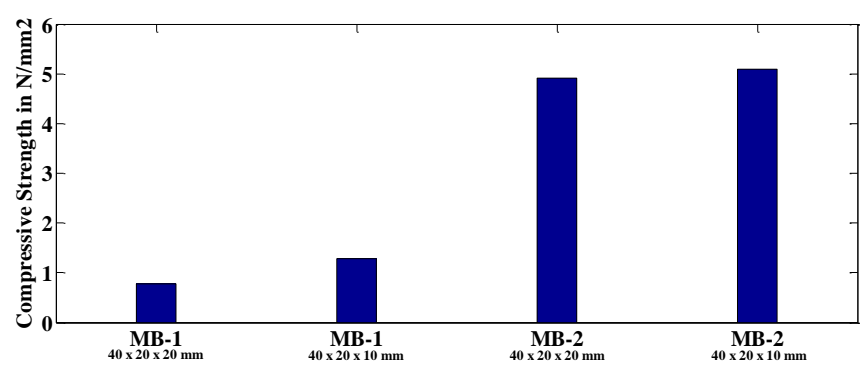

Figure 8. Compressive strength test results for MB-1 and MB-2 blocks

The compressive strength in the MB-2 blocks is observed as $4.92 \mathrm{~N} / \mathrm{mm}^{2}$ and $5.09 \mathrm{~N} / \mathrm{mm}^{2}$ for $20 \mathrm{~mm}$ and 10 $\mathrm{mm}$ size respectively. Whereas, in MB-1 blocks it is observed as $0.78 \mathrm{~N} / \mathrm{mm}^{2}$ and $1.28 \mathrm{~N} / \mathrm{mm}^{2}$ for $20 \mathrm{~mm}$ and 10 $\mathrm{mm}$ size respectively. Increase in compressive strength in MB-2 blocks may be due to the presence of silica oxides $(35.89 \%)$ and aluminium oxides $(34.36 \%)$ in spent catalyst, thus it acts as a cementitious material, hence contributing in strength development. Further, it is noted that spent catalyst is a very fine material having fineness $900 \mathrm{~cm}^{2} / \mathrm{g}$ which fills the pores between the paper sludge making it more dense compared to lime powder. Spent catalyst blocks are $10 \%$ denser than the blocks fabricated with lime. The average density of the MB-1 block is noted as $610 \mathrm{Kg} / \mathrm{m}^{3}$ whereas it is $671 \mathrm{Kg} / \mathrm{m}^{3}$ in case of MB-2 block. Both blocks fall in a light weight category. The compressive strength of the MB2 block is much higher compared to standard strength of any lightweight masonry block. MB-2 blocks could be used in construction of partition walls in framed structure. It also can take roof load in case of low rise structures.

\section{B. Creep test}

The dial gauge reading showing creep deformation under constant load is observed and tabulated in Table III and Table IV. The deformation versus time graph is plotted and is shown in Figure 9 and 10 for MB-1 and MB-2 block respectively.

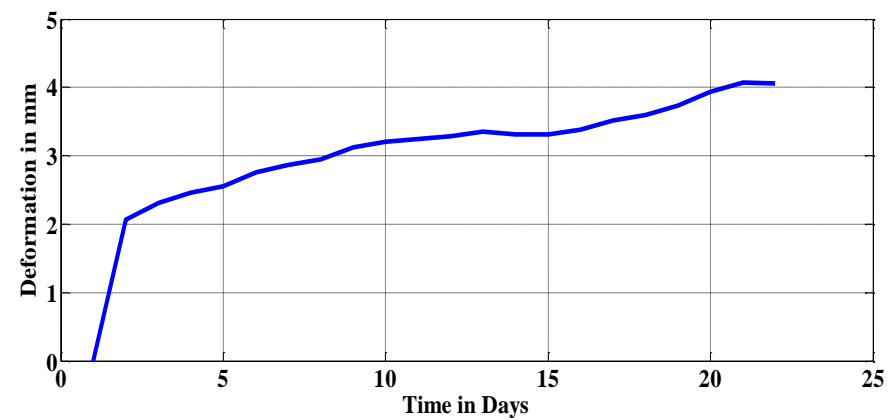

Figure 9. Deformation versus time for MB-1 block 
It is observed from the Figure 9 and 10 that the creep deformation for the first few hours up to day one is linear in nature. However, after two days time the time deformation curve for MB-1 and MB-2 blocks under constant stress of $7.36 \mathrm{~N} / \mathrm{mm}^{2}$ has monotonically increased showing the nonlinear behavior. The average strain was $0.92 \mathrm{~mm} / \mathrm{m}$ for MB-1 block, whereas it is $0.99 \mathrm{~mm} / \mathrm{m}$ for the MB-2 block. Further, it is observed that there is no increase in creep deformation after three weeks in case of MB-1 blocks, whereas similar

TABLE III: CREEP TEST RESULTS FOR MB-1 BLOCK

\begin{tabular}{|c|c|c|c|}
\hline $\begin{array}{c}\text { Time } \\
\text { (Days) }\end{array}$ & $\begin{array}{c}\text { Deformation } \\
(\mathbf{m m})\end{array}$ & $\begin{array}{c}\text { Strain } \\
(\mathbf{m m} / \mathbf{m})\end{array}$ & $\begin{array}{c}\text { Stress } \\
\left(\mathbf{N} / \mathbf{m m}^{2}\right.\end{array}$ \\
\hline 0 & 0 & 0 & 7.36 \\
\hline 1 & 2.06 & 0.95 & 7.36 \\
\hline 2 & 2.31 & 0.94 & 7.36 \\
\hline 3 & 2.46 & 0.94 & 7.36 \\
\hline 4 & 2.56 & 0.94 & 7.36 \\
\hline 5 & 2.76 & 0.93 & 7.36 \\
\hline 6 & 2.86 & 0.93 & 7.36 \\
\hline 7 & 2.95 & 0.93 & 7.36 \\
\hline 8 & 3.13 & 0.92 & 7.36 \\
\hline 9 & 3.21 & 0.92 & 7.36 \\
\hline 10 & 3.24 & 0.92 & 7.36 \\
\hline 11 & 3.29 & 0.92 & 7.36 \\
\hline 12 & 3.35 & 0.92 & 7.36 \\
\hline 13 & 3.31 & 0.92 & 7.36 \\
\hline 14 & 3.31 & 0.92 & 7.36 \\
\hline 15 & 3.38 & 0.92 & 7.36 \\
\hline 16 & 3.51 & 0.91 & 7.36 \\
\hline 17 & 3.60 & 0.91 & 7.36 \\
\hline 18 & 3.73 & 0.91 & 7.36 \\
\hline 19 & 3.94 & 0.90 & 7.36 \\
\hline 20 & 4.07 & 0.90 & 7.36 \\
\hline 21 & 4.06 & 0.90 & 7.36 \\
\hline
\end{tabular}

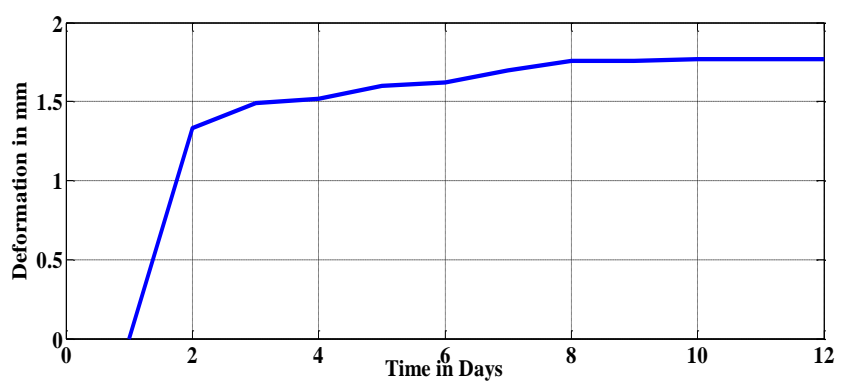

Figure 10. Deformation versus time for MB-2 block

TABLE IV: CREEP TEST RESULTS FOR MB-2 BLOCK

\begin{tabular}{|c|c|r|c|}
\hline $\begin{array}{c}\text { Time } \\
\text { (Days) }\end{array}$ & $\begin{array}{c}\text { Deformation } \\
(\mathbf{m m})\end{array}$ & $\begin{array}{c}\text { Strain } \\
(\mathbf{m m} / \mathbf{m m})\end{array}$ & $\begin{array}{c}\text { Stress } \\
\left(\mathbf{N} / \mathbf{m m}^{\mathbf{2}}\right.\end{array}$ \\
\hline 0 & 0 & 0 & 7.36 \\
\hline 1 & 1.33 & 0.997 & 7.36 \\
\hline 2 & 1.49 & 0.996 & 7.36 \\
\hline 3 & 1.52 & 0.996 & 7.36 \\
\hline 4 & 1.6 & 0.996 & 7.36 \\
\hline 5 & 1.62 & 0.996 & 7.36 \\
\hline 6 & 1.70 & 0.996 & 7.36 \\
\hline 7 & 1.76 & 0.996 & 7.36 \\
\hline 8 & 1.76 & 0.996 & 7.36 \\
\hline 9 & 1.77 & 0.996 & 7.36 \\
\hline 10 & 1.77 & 0.996 & 7.36 \\
\hline 11 & 1.77 & 0.996 & 7.36 \\
\hline
\end{tabular}

trend is seen in the blocks made with spent catalyst after two weeks. The creep deformation under constant load is relatively high in case of MB-1 block compared to MB-2 block. The creep deformation in both blocks is less and at present do not pose any structural threat. However, a long term creep for a period of one year needs to be investigated.

\section{Alternate Wetting and Drying}

Alternate wetting and drying cycles were carried out to investigate the moisture resistance, Water absorption, disintegration of the bond between paper sludge, filler and binding material and expansion and contraction of blocks. After 8 cycles of alternate wetting and drying it is observed that the water absorbed by the MB-1 block is almost $50 \%$ whereas in case of MB-2 it is $44 \%$. This clearly indicates that the blocks fabricated with paper sludge have very poor moisture resistance. However, there was no sign of disintegration of bond between the ingredients and also change in shape after 8 cycles of alternate wetting and drying. Further investigation needs to be carried out for longer duration to verify the durability of MB-1 and MB-2 block due to alternate wetting and drying cycle.

\section{Thermal Conductivity}

The results of thermal conductivity test carried out on MB-1 and MB-2 blocks are tabulated in Table V. It is evident from the table $\mathrm{V}$, that both masonry blocks are good thermal insulator. Thermal conductivity for MB-1 and MB-2 mix is approximately around $0.25 \mathrm{~W} / \mathrm{m} . \mathrm{K}$, which is much lower compared to conventional cement block.

TABLE V: THERMAL CONDUCTIVITY OF MASONRY BLOCKS

\begin{tabular}{|c|c|}
\hline Mix & $\begin{array}{c}\text { Thermal Conductivity (k) } \\
(\mathbf{W} / \mathbf{m} . \mathbf{K})\end{array}$ \\
\hline MB-1 & 0.247 \\
\hline MB-2 & 0.250 \\
\hline Conventional cement block & 1.002 \\
\hline
\end{tabular}

Thermal conductivity in conventional cement block is observed as $1.002 \mathrm{~W} / \mathrm{m} . \mathrm{K}$. The results clearly prove that paper sludge acts as a good heat insulator. MB-1 and MB-2 blocks could be used in construction of heat insulating walls.

\section{Conclusions}

The paper illustrates the study on masonry blocks fabricated from waste paper sludge, lime and spent catalyst. The test results reveal that the industrial waste, spent catalyst and waste papers could be successfully utilised in manufacturing masonry blocks. Both blocks fall under the light weight category as their densities are between $600-700 \mathrm{Kg} / \mathrm{m}^{3}$. The results obtained on compressive strength test indicate that both MB-1 and MB-2 blocks could be used as partition walls in framed structures. Further, the performance of the MB-2 block in terms of compressive strength is much higher than the MB-1 block, thus MB-2 block could also be used to take the roof load in case of low rise structure. The creep deformation under constant load is relatively high in case of MB-1 block compared to MB-2 block. There is no adverse effect of alternate wetting and drying cycles in terms of disintegration of the bond between paper sludge, filler and binding material and expansion and contraction of blocks. However, both blocks have shown poor performance in water absorption compared to conventional cement blocks. Thermal conductivity in both blocks is lower than the 
conventional cement blocks which indicates a good thermal insulating material.

\section{Acknowledgment}

The authors are grateful to the Dean, Associate Dean, postgraduate and research and Head, Department of Built \& Natural Environment, Caledonian College of Engineering, Oman for support and encouragement provided to them and for permission to publish the paper. Thanks are also due to The Research Council, Oman for funding the project under Faculty mentored undergraduate research project (FURAP).

\section{References}

[1] The Report: Oman Construction, Oxford Business Group, 2016

[2] E. Y.A. Okino and M. A. E. Santana, "Utilization of wastepaper to manufacture low density boards," Bioresource Technology, 73, pp $77-79,2000$

[3] J. S. Manuel, "How Do Paper Houses stack Up," Journal of environmental health perspective, Vol. 110, No. 3, A 126, 2002.

[4] J., A. Bai, J.M. Chaipanich, Kinuthia, M. O'Farrell, B.B. Sabir, S. Wild and M.H. Lewis, "Compressive strength and hydration of wastepaper sludge ash-ground granulated blastfurnance slag blended pastes," Cement and Concrete Research, 33, 1189-1202, 2003.

[5] T E.O. Soofia, S. Francoise, S. Nesen and Y. Simos, Comparative Study of the Thermal Performance of Building Materials. 23rd Conference on Passive \& Low Energy Architecture, Geneva, Switzerland ,6-8 September 2006.

[6] B. Fuller, A. Fafitis, and J. Santamaria, "The paper alternative," Civil Engineering, 76/5, pp. 72-77, 2006.

[7] J. A. G. Ochoa de Alda, "Feasibility of Recycling Pulp and Paper Mill Sludge in the Paper and Board Industries," Resources, Conservation and Recycling. pp 965-972, 2008.

[8] W. Matthew, "Developing a Low cost, Sustainable Housing Prototype using Recycled Waste Materials in Tijuana, Mexico," In. $25^{\text {th }}$ Conference on Passive and Low Energy Architecture, Dublin $22^{\text {nd }}$ to $24^{\text {th }}$ October, 2008.

[9] B. S. Mohammed, "Papercrete as infill Material for Composite Wall System," European Journal of Scientific Research, 34/4, pp.455-462, 2009.

[10] D. Jegatheeswaran, and R. Malathy, "An investigation on the production of construction bricks with waste papers," International Journal of Earth Sciences and Engineering, 3, pp. 77-82, 2010.

[11] I. Mohammed, M. A. Ismail, S. K. Lau, B. Muhammad, and Z. Majid, "Fabrication of Bricks from Paper Sludge and Palm Oil Fuel Ash," Concrete Research Letters, 1/2, pp 60-66, 2010.

[12] M. N. Abou-Zeid, E.H. Fahmy, H. Armanious, Y. El-Moghazi, S. Shaheen, and N. Talaat, "Use of waste materials in low cost housing," Proceedings, Annual Conference - Canadian Society for Civil Engineering, 2, pp. 1178-1187, 2011.

[13] D. Jegatheeswaran, and R. Malathy, "Utilization of papermill sludge in manufacturing of bricks - An environmental friendly approach," Pollution Research, 30/3, pp. 299-303, 2011.

[14] J. Santamaria, B. Fuller, A. Fafitis, "Structural properties of a new material made of waste paper," WIT Transactions on Modeling and Simulation, $13^{\text {th }}$ International Conference on Computational Methods and Experimental Measurements, Prague; 2 July 2007 to 4 July 2007, Code71360, 46, pp. 557-567, 2007.

[15] S.A. Masjaki, B.S. Mohammed, and H.M.A. Al-Mattarneh, "Hybrid Composite Wall System by using Local Waste: Panel of Cement Bonded Wood in Filled Papercrete," International Conference on Construction and Building Materials. pp 239-250, 2008.

[16] S. Naganatthan, A. A. Shakir, and K. N. B. Mustapha, "Development Of Bricks From Waste Material: A Review Paper" Australian Journal of Basic and Applied Sciences, Vol. 7(8), pp. 812-818, 2013.

[17] S. G. Patil, W. M. Habash, and H. A.M. Al Shidi, "Development of Self Compacting Concrete with Locally Available Spent Catalyst and Quarry Dust" International Journal of Civil and Structural Engineering, Vol. 3(1), pp. 21-26, 2016.
About Author (s):
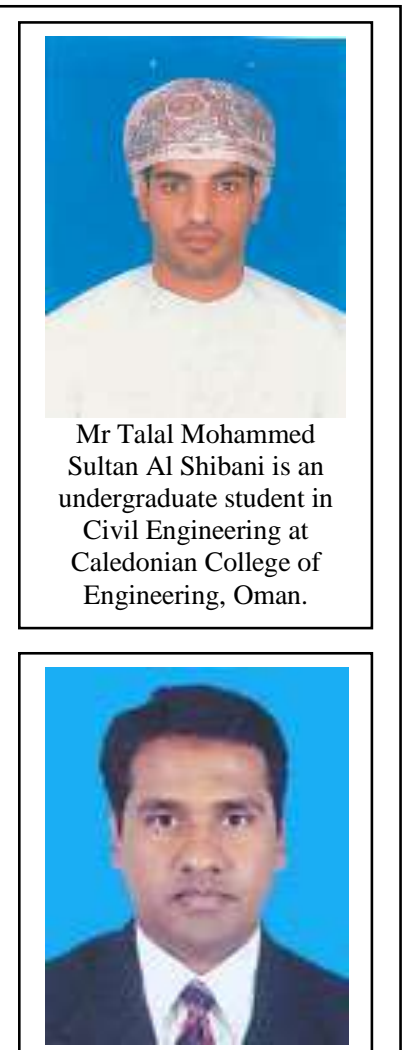

Dr Sanjay Govind Patil is an Assistant Professor Department of Built \& Natural Environment

Caledonian College of

Engineering, Oman.

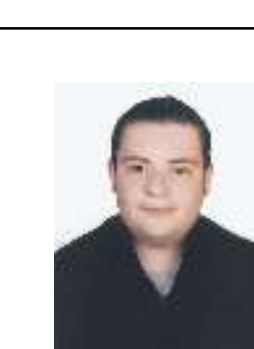

Mr Adnan M Nidal Shms Eddin is an undergraduate student in Civil

Engineering at Caledonian College of Engineering, Oman.
Mr Talal is Diploma holder in Civil Engineering and also has a Certificate course in Engineering Draftsman. Presently he is pursuing undergraduate course in Civil Engineering at Caledonian College of Engineering. He works for Ministry of Education, Oman in Civil Engineering section and looks after the construction of school projects. He is expertise in AutoCAD and his job involves preparing specifications and tender document. His areas of research interest is Concrete Technology and Waste Management.

Dr Sanjay Govind Patil has obtained his $\mathrm{PhD}$ in Civil Engineering from National Institute of Technology, Surathkal, Karnataka, India in 2012. His research interest involves in Coastal Engineering and application of artificial intelligence to solve complex civil engineering problems. He has published number of papers in these areas in reputed international journals and conferences. $\mathrm{He}$ is currently working on developing innovative construction material from industrial waste. Presently he is associated with Caledonian College of Engineering in Oman as Assistant Professor. He has 15 years of rich \& extensive experience in academics, strategic planning, curriculum development, teaching and academic administration. $\mathrm{He}$ is also involved in managing \& overseeing the administrative \& daily operations of the department, ensuring compliance with the policies and regulations.

Mr Adnan is pursuing undergraduate course in Civil Engineering at Caledonian College of Engineering. His areas of research interest is Concrete Technology and Waste Management. 